\title{
A Inclusão e suas práticas aspectos socioantropológicos da produção de materiais pedagógicos inclusivos para Surdos
}

Inclusion and its practices: socio-anthropological aspects of the production of Deaf-inclusive pedagogical materials

Ana Luisa Borba Gediel, Victor Luiz Alves Mourão e Isabela Martins Miranda

\section{(2) OpenEdition}

Journals

\section{Edição electrónica}

URL: http://journals.openedition.org/aa/3501

DOI: $10.4000 /$ aa. 3501

ISSN: 2357-738X

\section{Editora}

Programa de Pós-Graduação em Antropologia Social (UnB)

\section{Edição impressa}

Data de publição: 1 junho 2019

Paginação: 135-158

ISSN: 0102-4302

\section{Refêrencia eletrónica}

Ana Luisa Borba Gediel, Victor Luiz Alves Mourão e Isabela Martins Miranda, «A Inclusão e suas práticas aspectos socioantropológicos da produção de materiais pedagógicos inclusivos para Surdos», Anuário Antropológico [Online], v.44 n. 1 | 2019, posto online no dia 06 julho 2019, consultado o 28 abril 2021. URL: http://journals.openedition.org/aa/3501 ; DOI: https://doi.org/10.4000/aa.3501

\section{@ $\odot \Theta \Theta$}

Anuário Antropológico is licensed under a Creative Commons Atribuição-Uso Não-Comercial-Proibição de realização de Obras Derivadas 4.0 International. 


\title{
A Inclusão e suas práticas aspectos socioantropológicos da produção de materiais pedagógicos inclusivos para Surdos
}

\author{
Ana Luisa Borba Gediel \\ Universidade Federal de Viçosa - Brasil
}

Victor Luiz Alves Mourão Universidade Federal de Viçosa - Brasil

Isabela Martins Miranda Universidade Federal de Viçosa - Brasil

\section{Introdução}

A trajetória das políticas públicas voltadas para inclusão de populações minoritárias mostra que, apesar dos avanços que tivemos desde a Constituição de 1988, ainda há muito a ser feito. Se pensarmos, por exemplo, no âmbito econômico e distributivo, é histórica e negativamente notória a desigualdade social que marca nossa sociedade, em que pese a diminuição das diferenças de renda nos últimos anos (Dedecca, 2014). Em outro registro, os processos recentes de ampliação das políticas que envolvem o reconhecimento (Fraser \& Honneth, 2003; Fraser, 2006) da diversidade existente na sociedade brasileira também avançaram nas últimas décadas.

Algumas destas políticas são protagonistas no cenário de modificações do campo educacional envolvendo a educação de pessoas surdas. Podemos citar a Lei 10.436/2002, a qual dispõe sobre a Língua Brasileira de Sinais (Libras) e a reconhece como meio legal de comunicação e expressão; o Decreto 5.626/2005, que regulamenta a mencionada lei, estabelece a obrigatoriedade, por parte das instituições federais de ensino, a oferta de condições de comunicação, informação e educação às pessoas surdas, garantindo sua inclusão e estipulando a obrigatoriedade da disciplina de Libras nos cursos universitários de licenciatura, além de uma série de direitos correlatos. Ainda, a Lei 13.146 institui o Estatuto da Pessoa com Deficiência e visa garantir o exercício das liberdades e dos direitos das pessoas com deficiência e sua inclusão social. Posteriormente, em 2015, foi decretada a Lei ${ }^{\circ}$ 13.146/2015, conhecida também como Lei de Inclusão, que tem o objetivo de 
assegurar e de promover condições de igualdade. Destacamos, por último, a Lei $\mathrm{n}^{\circ}$ 13.409/2016, referente à reserva de vagas para pessoas com deficiência nas Universidades Federais brasileiras, garantindo-lhes o acesso no âmbito do ensino superior.

Este novo cenário pressionou um conjunto de novos arranjos nas instituições para a adequação dos espaços para a inclusão de pessoas com deficiência no ensino superior. De forma geral, a pauta de discussões concentrava-se anteriormente na formação de professores e nas adaptações curriculares e da estrutura física no âmbito da escola básica. No entanto, aquelas pessoas passam a adentrar as instituições de ensino superior, provocando a necessidade de transformações metodológicas e de formação docente. Esse espaço, anteriormente caracterizado como campo de discussões teóricas e de formação inicial para atuação futura com a inclusão, torna-se, também, alvo da necessidade imediata de adaptações referentes à inclusão. Neste artigo, apresentamos algumas reflexões relativas à experiência de uma instituição de ensino superior, na região da Zona da Mata Mineira, que teve alunos Surdos matriculados em diferentes áreas de ensino e aderiu a algumas estratégias para a inserção e a permanência dos alunos em sala de aula. Como recorte da pesquisa e como posicionamento frente às diferentes discussões no campo da Deficiência, Surdez e Movimentos Surdos, a utilização do termo Surdo com sua letra inicial maiúscula foi escolhida, seguindo uma convenção estabelecida por um grupo de lideranças Surdas envoltas nos espaços acadêmicos. Em específico, identificação refere-se aos grupos de pessoas surdas que utilizam a Libras como primeira língua e usufruem dessa como meio político, cultural e identitário de reconhecimento (Padden \& Humphries, 2006). No presente trabalho, Surdo é definido (em oposição a surdo) como uma categoria êmica, ou seja, utilizamos a nomenclatura conforme o estabelecido e considerado pelos próprios sujeitos.

A ideia inicial da pesquisa centrava-se no mapeamento das tecnologias que estavam sendo utilizadas para promover o ensino/aprendizagem da Libras na instituição. Tal recorte deve-se ao fato de que a instituição é reconhecida pelo seu investimento em Tecnologias da Informação e Comunicação (TIC's), entendida como um conjunto de recursos tecnológicos que, ao estarem integrados entre si, podem proporcionar a autonomia e/ou a comunicação de vários tipos de processos existentes no ensino e na pesquisa científica, mediando os processos informacionais e comunicativos (Da Silva, 2009; Imbérnom, 2010).

Para encontrar os profissionais na instituição que estavam atuando na elaboração das TIC's realizamos um Mapeamento por Redes de Contato (Barnes, 1987). 
A partir dessa metodologia, observamos a construção dos laços entre as pessoas da instituição que atuavam no desenvolvimento de TIC's e verificamos a sua capacidade de agência e de influência nesse sistema. Ao longo do processo de mapeamento nos deparamos com o projeto de criação de materiais didáticos bilíngues (Libras/Português), voltado para o ensino/aprendizagem em um dos cursos da instituição, o qual passou a ser nosso foco de análise. Passamos a acompanhar o percurso de constituição de demandas do aluno, a organização de professores, de gestores, da equipe técnica e do espaço institucional para o estabelecimento de condutas de modo a responder a essas demandas.

Durante o período de mapeamento e de contato com os profissionais envolvidos no processo de elaboração de TIC's inclusivas, identificamos e acompanhamos a construção de materiais didáticos, os quais começaram a ser desenvolvidos especificamente para as aulas de um aluno Surdo. Tal ação tornou-se protagonista no contexto de desenvolvimento de tecnologias para inclusão na instituição e, a partir de então, vários olhares voltaram-se para esse processo. A criação das denominadas "aulas sinalizadas" surgiu a partir de um grupo interdisciplinar, que elaborou um projeto com o objetivo de criar formas de apoio para que o aluno conseguisse acompanhar o andamento das disciplinas no ensino superior. Este percurso nos possibilitou observar também os conflitos e as situações de estigmatização dos sujeitos (Goffman, 2012). Nesse contexto, descrevemos os agentes implicados nas ações que passaram a ser desenvolvidas e as interlocuções realizadas para o atendimento das demandas advindas via políticas públicas e a real situação de entrada de um aluno Surdo na instituição.

\section{Abordando os sujeitos: impressões do campo}

Os desdobramentos iniciais do projeto e a descrição dos olhares que permearam o campo partiram da observação participante, notas e diários de campo (Cardoso de Oliveira, 1996). Ao acompanhar as ações que envolviam as TIC's na Instituição de Ensino Superior (IES) estudada, passamos a visualizar diferentes perspectivas para a elaboração e a execução das políticas públicas inclusivas.

O primeiro contato com os interlocutores da pesquisa ocorreu no meio do ano de 2016, com o mapeamento daqueles professores e gestores que atuavam em projetos e ações voltadas para o uso das TIC's na instituição. Assim como indicado por Barnes (1987) para a realização do mapeamento de redes, o primeiro contato foi feito com o gestor dos projetos de extensão da Instituição, o qual possuía uma 
visão ampla de todas as iniciativas. Desse modo, chegamos aos projetos existentes na instituição e em quais setores ou departamentos estavam concentrados, além de entender os vínculos entre os projetos.

Tal contato possibilitou descobrirmos as unidades da instituição envolvidas com o tema da pesquisa. O responsável citou várias que atuavam na elaboração desses materiais, como a Unidade de Ensino à Distância, de Línguas, de Informática e o setor de acessibilidade, assim como seus representantes. Dessa maneira, criou-se uma rede de contato, em que cada um dos entrevistados citava outros profissionais influentes da rede, acreditando que o colega poderia enriquecer o trabalho da pesquisa. Com isso, consolidou-se a rede de contatos, que neste artigo ficou restrita à Unidade de Ensino à Distância, pois é a única parte da instituição que produz materiais didáticos com a finalidade de suporte para estudo dos alunos surdos. A partir disso, os colaboradores da pesquisa são evidenciados conforme o quadro que segue:

\section{Quadro 1: Identificação dos entrevistados}

\begin{tabular}{|c|c|}
\hline Nome & Vínculo para atuação no projeto \\
\hline João Daniel & Funcionário da Unidade de Ensino à Distância \\
\hline João Eduardo & Funcionário da Unidade de Ensino à Distância \\
\hline João Felipe & $\begin{array}{c}\text { Estagiário da Unidade de Ensino à Distância; } \\
\text { único da equipe que possui conhecimentos em } \\
\text { Libras. }\end{array}$ \\
\hline Maria Beatriz & Diretora da Unidade de Ensino à Distância \\
\hline
\end{tabular}

Os nomes das pessoas, dos setores e da instituição foram preservados por questões éticas. Ao passo que fomos mapeando e encontrando as pessoas, fomos denominando as mulheres de "Maria" e os homens de "João", seguido por segundo nome aleatório com a inicial de letra em ordem alfabética de acordo com a ordem que apareceram no mapeamento. Em relação à formação, temos uma equipe interdisciplinar, em que João Daniel é o único que tem sua formação voltada para a área de Informática. João Eduardo tem formação na área da Comunicação, João Felipe, embora desempenhe papel vinculado à área de Libras, tem formação nas Ciências Sociais e, por fim, Maria Beatriz tem formação voltada para a Educação a distância. Desse modo, três dos quatro colaboradores da pesquisa advêm do campo das Ciências Sociais e Humanas. 
Após o estabelecimento da rede, passamos para a segunda etapa da pesquisa, com a realização de entrevistas com os membros das equipes responsáveis pelo desenvolvimento de materiais. Todas as entrevistas foram de cunho semiestruturado (Triviños, 1987), e os professores assinaram o termo de consentimento livre e esclarecido, o qual informa o sigilo da pesquisa ${ }^{1}$

A partir das entrevistas, tivemos a oportunidade de conhecer mais a respeito de cada projeto citado. A observação participante e o acompanhamento de algumas ações nos levaram a um projeto específico, voltado para um aluno Surdo. Tal destaque se deve ao fato de que os olhares dos próprios informantes estavam voltados para esse projeto, o qual pretendia a criação de uma versão das aulas narradas para aulas sinalizadas. As aulas narradas são entendidas como um modelo de exposição de conteúdo didático em formato de vídeo-aulas, utilizado na instituição como material disponível para acesso teórico aos conteúdos das disciplinas realizadas à distância. Desse modo, a adequação desse modelo pedagógico para aulas sinalizadas possibilitaria o entendimento do conteúdo para um aluno Surdo que havia se matriculado na instituição.

\section{O projeto de criação de materiais didáticos e a reflexão autóctone}

O cenário de entrada de alunos Surdos no contexto universitário tem proporcionado trocas de saberes, adição de agentes com conhecimentos educacionais e linguísticos específicos, além das adaptações no cenário de sala de aula. Santos (2015) apresenta um panorama de pesquisas que remetem ao processo de inclusão no ensino superior, as quais apontam para um número ainda pequeno de pessoas surdas matriculadas. Também, em seus achados, descreve a importância dos profissionais tradutores e intérpretes de Libras/Português para realizar a mediação linguística durante as aulas, visto que a partir desse mapeamento realizado pela autora não há a percepção de uma mudança considerável na didática dos professores com a entrada desses alunos. Percebemos, então, a criação de algumas iniciativas, como o projeto mencionado. Este nasceu de uma demanda relativa à entrada de um estudante Surdo que necessitava de materiais didáticos para levar adiante seus estudos. Ainda que a universidade oferecesse intérpretes para as aulas, os momentos de estudo fora da sala apresentavam problemáticas anteriormente não identificadas, qualificadas retrospectivamente como "drama” por João Felipe: “Só o intérprete na sala de aula não era o suficiente porque toda a interação em Libras fica restrita na sala de aula. Se o Surdo quisesse rever o material e tal, ele não teria possibilidade na língua dele, 
se não fosse com mediação do intérprete e isso dentro da sala de aula. E fora da sala de aula?".

A segunda maior instância administrativa da instituição, a coordenação do curso da área das exatas, os professores de diferentes departamentos e o setor de acessibilidade da instituição, preocupados em atender às especificidades do aluno, contataram a Unidade de Ensino à Distância para que produzisse materiais capazes de atender tal demanda.

Inicialmente, o grupo de profissionais entendia que era necessário apenas legendar as aulas narradas - formato de apresentação do conteúdo da aula em vídeo gravado em estúdio pelo professor - das disciplinas. Nesse estágio, a percepção da equipe responsável pelo projeto demonstrava o desconhecimento em relação à especificidade linguística do sujeito Surdo, que tem a Libras como primeira língua e a Língua Portuguesa como segunda língua. Por isso, o grupo de professores das exatas e a equipe de tecnologias considerava que a questão seria resolvida com a adição de uma legenda nos conteúdos vinculados à disciplina, uma espécie de aula narrada legendada. Estimava-se que, em poucos meses, os materiais estariam prontos para uso. No entanto, assim que as atividades tiveram início, a falta de conhecimentos por parte da equipe em relação às especificidades culturais e linguísticas das pessoas Surdas foi o primeiro entrave reconhecido. Como menciona Maria Beatriz, diretora da Unidade, "um projeto que a princípio parecia ser simples, chegar aqui e fazer uma aula narrada para atender e viu-se que era muito complexo que isso". Havia, portanto, uma subestimação em relação às dificuldades de realização do projeto, tendo em vista a falta de conhecimento no que tange à "complexidade" da Libras e do modo como o Surdo interage, comunica-se e aprende.

Esse momento foi permeado por várias características que identificamos semelhantes ao pontuado nos estudos de Goffman (2012), em torno de uma situação normal-estigmatizado: perplexidade, desconforto, inquietação, momento esse no qual o grupo começou a identificar a necessidade de um conjunto de ações, as quais não eram explícitas na legislação e que deveriam ser articuladas de maneira interdisciplinar, conforme afirma Maria Beatriz:

[...] é um desafio diferente porque são áreas temáticas diferentes, pessoas diferentes e que nos tiram um pouco dessa zona de conforto de atuar em coisas que você domina no dia a dia e isso acaba que mexe com essa estrutura que já tá consolidada e você tem que buscar, tem que estudar, aí você percebe, "ah, eu não tenho nem 
essa competência, nem essa habilidade", preciso identificar pessoas para virem compor, para ajudar esse grupo [...] (grifos nossos).

A elaboração das aulas sinalizadas teve início com um conjunto de questões pragmáticas que deveriam ser resolvidas para dar continuidade à ideia proposta: era necessário organizar uma equipe de trabalho, elaborar o projeto de treinamento dos envolvidos na execução e planejar a articulação das diferentes áreas que iriam atuar colaborativamente. Esse esforço organizacional deveria ainda estar de acordo com as demandas que envolvem o âmbito das políticas públicas inclusivas de maneira mais geral, para além do caso específico.

Maria Beatriz relata ainda que a partir da compreensão das dificuldades inicialmente subestimadas que o grupo precisou “contratar alguém que soubesse Libras para compor nosso quadro de estagiários, tivemos que trabalhar com estagiários voltados para essa área, fazer parcerias ou trabalhar mais conectados com os intérpretes [...]”. A percepção da ausência de competências, de conhecimentos e de habilidades acumuladas para concretizar a tarefa estipulada levou à busca de mais integrantes para a equipe. Foi quando ocorreu a contratação de um estagiário com conhecimentos na Libras, João Felipe, para compor a equipe responsável pela produção do material. A partir desse momento, a organização da equipe, a divisão de atividades e responsabilidades e os próprios produtos do projeto são reformulados.

Esse processo levou a uma reflexão coletiva na qual três questões emergiram: 1) necessidade de reorganização o material didático apostilado em uma apresentação compatível com as especificidades do modo de comunicação e aprendizagem do aluno Surdo, com a utilização da Libras e de sinônimos de algumas palavras técnicas por classificadores ${ }^{2}$ e explicação do conceito (Quadros \& Karnopp, 2004); 2) a Libras, por ser uma língua espaço visual, requer o uso de imagens associadas aos conceitos para trazer a explicação para o universo do aluno Surdo; desse modo, as imagens ilustrativas apoiam a compreensão; 3) constatou-se uma falta de tradução de conceitos da área das exatas para a Libras.

A partir das constatações pela equipe, chegou-se à conclusão de que nem somente a legenda, tampouco a interpretação de conteúdos para a Libras utilizando os mesmos slides, previamente criados pelos professores para as aulas, não garantiria o acesso do aluno aos conhecimentos que estavam sendo ministrados nas diferentes disciplinas nas quais ele estava matriculado. Era necessária a elaboração de conteúdos didaticamente reformulados, adequando-os aos três pontos acima mencionados. Isso também demonstrava a necessidade de criar de um glossário especí- 
fico da área para que o material fosse considerado inclusivo e didaticamente eficaz.

Todos esses fatores linguísticos, conceituais e metodológicos surgem em um contexto complexo, com pessoas integrantes da equipe possuindo diferentes perspectivas a respeito do tema, relacionadas às especificidades da pessoa Surda e das ações necessárias frente ao cumprimento das políticas públicas.

O projeto foi então na direção de conseguir capacitar a equipe no processo de reformulação da equipe e das rotinas de atividades, para posteriormente lidar com o desafio de criar materiais didáticos para Surdos, para formação referente aos modos de aprendizagem e de interação das pessoas Surdas que utilizam a Libras. Entendemos que esse processo permeia a execução das políticas públicas, no sentido de localizar o que é transcendente; complexificar o homogêneo - trata-se de evitar cair na concepção autocongratulatória dos textos oficiais para desenvolver uma perspectiva que consiga captar as "práticas etnopolíticas na efetivação de direitos de cidadania” (Fonseca et al. 2016, p. 11). Essas práticas que envolvem os sujeitos, os objetos, as linguagens, as línguas, as redes, precisam ser mobilizadas para alcançar os objetivos da política pública inclusiva.

\subsection{A tomada de consciência mediada}

Com a reorganização inicial da equipe, o estagiário estaria responsável pelas atividades relacionadas a Libras no âmbito da produção do material didático. No entanto, sua atividade efetiva ultrapassou as funções inicialmente previstas, abarcando a função de coordenador geral das atividades do projeto, de apresentador da cultura Surda aos membros leigos da equipe do projeto e de mobilizador dos vários grupos que o compunham. João Felipe relembra dessa maneira o momento inicial de sua participação no projeto:

eu entrei na [Unidade de Ensino à Distância] em maio [e] comecei a fazer o estágio aqui para o material ficar pronto para o mês de agosto [...] Uma das primeiras coisas que eu procurei saber assim e fazer foi: vamos organizar uma equipe, [e] para organizar essa equipe não tinha nem projeto [...]. Veio [tudo] numa desorganização [...] Meu depoimento é meio crítico, porque não foi [nada] pensado, veio assim, a demanda veio e 'ó' : 'a gente precisa de material para o período que vem'.

Novamente, a ausência de competências para levar adiante o projeto dentro do prazo estabelecido se tornou explícita. Desde os anos 1990, com as reivindicações dos movimentos Surdos, do envolvimento da academia e do endossamento de 
documentos legais, houve também uma construção interdisciplinar do campo de atores sociais que envolve a Libras. Surge, então, um nicho de atividades que insere a língua e as experiências advindas desse grupo de pessoas em projetos educacionais nas frentes do ensino, pesquisa e extensão (Brito, 2016). A participação desses sujeitos no campo acadêmico, por exemplo, trouxe influências na própria construção de sentidos das categorias científicas que estão sendo criadas na Libras, levando em consideração o olhar do próprio movimento Surdo.

No entanto, há um processo de adequação e, no caso da produção do material didático, eram "poucas pessoas, só eu no caso que sabia um pouco da Libras", como afirma João Felipe. Essa constatação leva à reformulação das funções, e João Felipe se assume enquanto "cientista social":

o meu papel nesse momento foi de mediador, então eu entrei com o papel de cientista social mesmo, articulei a equipe, fui articular as pessoas, fui chamar as pessoas, organizar grupos de estudo, as reuniões, discussão sobre o que era língua de sinais, discussão de como usar as tecnologias até tem um texto que gente discutiu da Marianne Stumpf, uma Surda especialista na escrita da língua de sinais, e aí discutimos esses textos e eu fiquei na parte de produzir relatórios, então eu sempre produzia relatório e mandava para o grupo e articulava: "pessoal, vamos reunir" e tal, os dias, então esse foi o meu papel, de trazer os intérpretes, então os intérpretes começaram a participar das reuniões sempre tinha dois ou um intérpretes [do setor de acessibilidade], os Surdos, conseguia uma articulação, aproximei o estudante Surdo da equipe para ele participar também do processo nesse primeiro momento, nesse primeiro semestre.

João Felipe se assume como aquele que, além de ter conhecimento fundamental da língua, trabalha para além desta habilidade, atuando principalmente como um mediador de culturas, de línguas e práticas sociais distintas, de maneira a colocá-las em contato e permitir que o trabalho coletivo de produção dos materiais didáticos aconteça. Ele organizou e promoveu durante dois meses um grupo de estudos para conscientização sobre a língua e surdez, composto pelos funcionários da unidade, os estagiários do curso de exatas, os intérpretes vinculados ao setor de acessibilidade e o estudante Surdo. De tradutor de textos ele passa a mediar culturas e promover a reflexividade sobre os modos distintos de ser e de aprender, possibilitando o aperfeiçoamento das competências ligadas à produção de materiais didáticos. Aqui a autopercepção deste cientista se aproxima muito da problemática instaurada de 
uma dupla hermenêutica que permite apresentar, traduzir e comunicar redes de significados que pertencem a certos contextos de vida social a outras pessoas que não tem acesso a eles (Giddens, 2007). Desse modo, o estagiário atuou no sentido de realizar uma análise crítica do social e, consequentemente, provocar transformações sociais no sentido de uma maior reflexividade.

A partir de outro ponto de vista, é possível compreender a diferenciação de olhares dos participantes do projeto, das concepções em relação ao movimento Surdo e aos espaços ocupados pela língua e por seus interlocutores. João Felipe assume a posição contrária à categoria deficiente, que conforme Assis (2011), está vinculada à concepção biomédica, que caracteriza a pessoa a partir da perda auditiva. A promoção das ações foram encaminhadas de acordo com uma perspectiva que se alinha à categoria surdo(s $)^{3}$. Ambas as posições são legitimadas e assumem caráter político, uma voltada para a perspectiva da reabilitação e aproximação do sujeito à normatização que pode ser adquirida por meio de tecnologias, como o aparelho auditivo ou o implante coclear. E, a outra, está respaldada pela particularidade linguística, que consecutivamente, relaciona-se à construção de identidades e cultura alinhadas à especificidade da língua. As ações de João Felipe, além de serem conduzidas pela afinidade à categoria surdo(s), evidencia também que a equipe se posicionava de maneira diferente em relação ao modo de entender os sujeitos alvo da produção do material didático ou ainda não tinham um conceito formado a respeito de tal discussão. As interações da equipe e o processo de aproximação das crenças referentes à categoria surdo(s) previamente obtidas por João Felipe foram sendo incorporadas por meio de textos acadêmicos, vídeos com depoimentos de pessoas Surdas descrevendo a importância da língua em suas vidas e a apresentação de pesquisas que levavam ao entendimento que os materiais didáticos elaborados com o uso da Libras e o suporte imagético ampliavam o desempenho de apreensão de conhecimentos das pessoas Surdas que utilizavam essa língua como principal meio de comunicação.

Em aliança com essas atividades de estudos e de apresentação do modo de ser Surdo, a divulgação de um fórum promovido pelo Instituto Nacional de Educação de Surdos (INES) motiva parte da equipe a participar e conhecer um dos locais considerado ícone do movimento Surdo na perspectiva que João Felipe havia apresentado ao grupo. Nesse evento, foram expostos trabalhos relacionados à construção do projeto e foi feita também uma visita à TV INES, onde são produzidos materiais audiovisuais parecidos com o objetivo do projeto. Maria Beatriz descreve que, após 
a visita à instituição, houve uma maior integração do grupo e entendimento do foco para as reais necessidades de desenvolvimento das atividades, conforme descrito a seguir: "As visitas que foram feitas no INES e formou-se um grande grupo aqui na [Unidade de Ensino à Distância] buscando conhecer um pouco mais o que que é a Libras, procurando saber que tipo de material de didático seria mais adequado pra atender mais, não só o Surdo mas o ouvinte também”.

Isso suscitou, na equipe responsável, um processo de tomada de consciência da categoria instituída, a qual evocava o discurso da diversidade e das diferenças que envolvem a condição surda e, por conseguinte, da necessidade de se capacitar para levar adiante o projeto. João Daniel reconhece o aspecto diferencial do modo de ser Surdo, se afastando da negatividade do diagnóstico médico típico do senso comum: "os Surdos pensam diferente, o mundo deles é diferente do nosso, isso não é ruim é só diferente, a gente tem que entender isso". Em uma fala retrospectiva, ele consegue identificar a principal problemática inicial do projeto, relativa à falta de conhecimento do modo de interagir e aprender do Surdo: "A grande dificuldade inicial foi entender o público alvo porque nós não somos Surdos e não temos contato com pessoas Surdas o tempo todo aqui”. E o modo de ser Surdo passa, na compreensão dos próprios entrevistados, pela percepção de que o Surdo possui uma língua diferente, específica e distinta, e que coloca problemáticas no âmbito pedagógico-comunicacional.

Na acepção biomédica da deficiência são consideradas apenas as limitações sensoriais, fisiológicas e/ou cognitivas em relação a um parâmetro de normalidade auditiva; já no sentido da diferença, construído no âmbito da equipe, essa condição é construída a partir das elaborações do próprio grupo, que pretende uma identificação cultural ligada à questão linguística, no ponto de vista êmico. Os Surdos se constroem enquanto grupo minoritário para a reivindicação de direitos sociais e educacionais. Assim como menciona Carniel (2013), o campo da educação torna-se um espaço de construção de significação para as políticas que estão sendo implementadas, as quais são autorizadas seguindo os rumos adotados pelo Estado. No entanto, esse campo é fecundo para disputas de poder por meio de práticas estabelecidas nas instituições, as quais possibilitam a invenção pedagógica, conforme as categorias e crenças apropriadas pelos agentes envolvidos.

Isso é evidenciado nos discursos dos colaboradores da pesquisa quando o grupo se posiciona politicamente diante do debate sobre a surdez, assumindo a perspectiva de sua especificidade linguística, não tomada como uma deficiência e sim como uma diferença. Levando em conta esse viés, as pessoas Surdas formam grupos e intera- 
gem em associações, fortalecendo posições ideológicas e políticas e reivindicando visibilidade, acessibilidade e inclusão. Assim, essa perspectiva coloca que a Língua de Sinais desafia os padrões a serem aceitos na sociedade, mesmo tendo importância significativa para o grupo de pessoas Surdas que a utiliza, com forte papel de demarcação da cultura sentida e expressa corporalmente. Ao considerarmos as categorias de "normalidade" e "anormalidade" definidas por Michael Foucault (2001), os Surdos podem ser pensados como "anormais", da mesma maneira que o autor se refere às pessoas que estão fora dos padrões do direito civil ou do direito religioso. Os indivíduos descritos pelo autor, como aqueles deformados por enfermidades ou diferentes dos padrões sociais legitimados "normais", não estavam previstos na área do direito ou religião. Isso os tornava entraves no processo de tomada de decisões sociais. Ainda hoje, percebemos que, embora haja mudanças na legislação, a problemática de como lidar com essas pessoas e inclúí-las em diferentes espaços permanece.

João Daniel afirma que, para conseguir produzir o material didático, é necessário "saber da importância da valorização da cultura Surda [...]. Porque as pessoas acham que os Surdos sabem português fluentemente, as pessoas não sabem que a primeira língua deles é Libras, muita gente nem sabe que a Libras é uma língua oficializada no Brasil e é a segunda”. João Eduardo, discorrendo sobre as especificidades do modo comunicacional do Surdo e da problemática de produção de material didático para este público, faz sobre isso a seguinte reflexão: "você tem que ter uma preocupação para que realmente tenta se colocar no lugar do Surdo para ver se você conseguiria realmente entender aquilo”. João Felipe reforça tal entendimento da especificidade comunicacional-linguística dos Surdos e o impacto desta compreensão na produção de materiais didáticos:

é como se fosse a segunda língua dele e não a primeira língua dele, e aí começou a surgir os problemas, as problemáticas, [...], qual problemática? Que é uma outra língua, é uma outra modalidade linguística, é mais difícil para o Surdo ler uma palavra em português do que às vezes ver uma sentença em Libras, ainda mais para esse Surdo [o estudante, que] tinha um bom domínio da língua brasileira de sinais

As especificidades da Libras, enquanto língua gestual e imagética, foram elaboradas pela equipe como um próprio modo de organização interna do trabalho de construção dos materiais didáticos. Para João Eduardo, 
a Libras é uma linguagem extremamente objetiva, então os Surdos têm a necessidade de serem extremamente objetivos, se você está colocando uma imagem que ela não é muito óbvia em cima da mensagem que você quer colocar, isso não é uma boa imagem, arruma outra que vai bater o olho e vai ligar num conceito, se tiver uma subjetividade ali não é muito bom, eu prefiro você ser direto e mais objetivo possível.

Observa-se o que o entrevistado nota como sendo "objetividade" poderia ter sido chamado de concretude imagética: o sentido e o significado devem ser concretos e visuais, o que destoa do modo como a ciência, em sua parte teórica e abstrata, se especializou em desenvolver. Nas falas apresentadas acima, percebe-se o processo reflexivo de tomada de consciência da diferença negada em relação ao Surdo, da "complexidade" que é a comunicação através da língua de sinais. Glat e Pletsch (2010), consideram que para uma educação inclusiva é necessário mais do que adaptações, é preciso buscar uma nova concepção curricular, reconhecendo as especificidades dos alunos.

A tomada de consciência e de aprendizagem em relação à cultura Surda e do modo de aprender do Surdo foi fundamental para o processo, concomitante e posteriormente, de construção do material didático. A Unidade de Ensino à Distância concluiu que a proposta de legenda simples não seria eficaz ao aprendizado do estudante: seria necessário realizar algo na primeira língua desse aluno, em Libras. A desnaturalização do português escrito como primeira língua dos Surdos foi, assim, um processo fundamental dessa tomada de consciência para que a equipe se afastasse da concepção inicial da produção de materiais didáticos voltados para Surdos enquanto legendagem do material disponível para se aproximar de um processo que envolvesse a tradução/interpretação dos conteúdos didáticos das disciplinas. Isso adicionou um nível de complexidade ao processo inicialmente imaginado que implicou em uma reformulação do projeto e na percepção de uma série de problemas que deveriam ser enfrentados. Aqui, percebemos igualmente que em consonância com outras pesquisas, os membros da equipe de produção de material didático funcionam como "intermediários" pensantes, reflexivos, que se voltam para a construção de pontes que permitam não só a realização da atividade restrita a eles colocada (qual seja, a produção de materiais didáticos acessíveis) mas que problematizam, de maneira mais ampla, o lugar e os modos de acesso à cidadania e ao reconhecimento daqueles que são seus objetos/sujeitos de ação (Fonseca et al., 2016). 


\subsection{Desenvolvimento da metodologia de criação de materiais didáticos acessíveis}

Um grande desafio foi criar uma metodologia para elaboração do material didático acessível. A unidade já possuía vários modelos de construção de materiais didáticos, mas nenhum foi capaz de prover acessibilidade aos Surdos. É nesse momento que a já citada visita à INES foi fundamental para averiguar as metodologias utilizadas na criação de materiais acessíveis em Libras, como explicita João Daniel:

O que a gente percebeu lá [na TV INES] é que até existem metodologias, mas existem várias formas de se fazer e cada lugar tem um jeito. E esse jeito é gerado a partir da particularidade da equipe que eles têm, porque o ideal num caso desses é que tenha Surdos na equipe, no caso deles têm e dentro da TV INES tem várias maneiras de fazer o mesmo produto porque tem um Surdo que ele prefere pegar uma câmera de computador, pegar o texto em português e aí ele sinaliza e aí ele manda aquilo para o colega dele revisar, ele manda para o intérprete, tem uns que preferem que o intérprete faça o texto e aí o Surdo vai analisar o vídeo, então lá dentro da TV tem vários Surdos, vários ouvintes, vários intérpretes, eles têm formas diferentes de trabalhar o mesmo material, métodos diferentes mas para gerar um mesmo vídeo no final, depende da [composição da] equipe.

A reflexividade possibilitou demonstrar que a metodologia e a construção técnica dos materiais estão atreladas à composição social diversa da equipe voltada para este objetivo: ou seja, o tecnograma (o complexo de técnicas, tecnologias, materiais, equipamentos e produtos) é correlato ao sociograma (o complexo de pessoas, técnicos, professores, estudantes, etc.) que são arroladas para a construção dos materiais didáticos acessíveis (Latour, 2000). E é essa correlação entre a particularidade da equipe e a composição específica tecnológica que promove um tipo particular de resolução metodológica da problemática de criação de conteúdo didático.

Como mencionado, outro enfrentamento do projeto foi a falta de sinais específicos do jargão técnico da disciplina. Vários termos técnicos não possuíam sinais, e isso dificultava o trabalho. Isso decorre, em parte, de outras especificidades relativas à Libras. A Libras sempre foi considerada uma língua marginalizada, em especial por ser uma língua visual, que começou a ganhar proeminência apenas no século XXI. É importante ressaltar que ela é a língua da comunidade Surda e eles conseguem se expressar como qualquer pessoa ouvinte, inclusive em conceitos abstratos (Gesser, 2009). Ela possui gramática e suas variações são dadas em configurações de mãos, expressões faciais e também corporais, que provêm sentido à língua (Quadros 
\& Karnopp, 2004). Trata-se de uma língua em processo de reconhecimento e de expansão do seu léxico. Os estudos linguísticos das línguas de sinais no Brasil são muito recentes e isso gera uma lacuna de palavras, conceitos e expressões, principalmente em áreas pouco exploradas ainda, como os termos técnicos nas áreas das ciências exatas.

Neste âmbito, buscou-se capacitar a equipe a partir dos processos de criação de sinais da Libras. Uma fonte fundamental de informação foi uma comunidade de Surdos no Facebook na qual havia um trabalho de criação de sinais. A equipe contou com o apoio da pessoa surda, beneficiada pelo material didático, para auxiliar no processo de criação dos sinais e no feedback avaliativo de outras pessoas surdas. Primeiramente, ele entrou em um grupo de pessoas surdas sinalizantes que realizavam cursos no campo das ciências exatas do país, a partir de uma mídia interativa digital, para conhecimento e troca de sinais que vinham sendo utilizados e criados. Posterior a este momento, tendo em vista que um número considerável de conceitos ainda não tinha sinais, o aluno Surdo, em conjunto com a equipe de criação de material didático, começou o processo de mapeamento dos sinais específicos e daqueles que ainda não haviam sido registrados por meio de sinais convencionados pelos Surdos participantes do contexto acadêmico e inseridos nos movimentos de liderança Surda.

Após a elaboração prévia de um sinal para um conceito realizada pelos intérpretes e pelo Surdo, em conjunto com o monitor da área, este sinal era enviado para lideranças surdas, residentes em diferentes regiões do país, para que houvesse uma avaliação acerca da criação de determinado sinal. Conforme João Felipe, a interação das pessoas Surdas por meio de mídias de interação online para a catalogação e constituição dos sinais específicos de determinada área acadêmica auxiliaram aprofundar a reflexão sobre o modo de aprender Surdo: "como ele [o estudante Surdo] e mais outros Surdos criaram um grupo no Facebook das [ciências exatas] para propor sinais para conceitos que não existiam, [...] a gente estudou como que foi a interação a partir do Facebook".

Nesta etapa, pensou-se em criar os sinais que ainda não existiam, com um método que envolvia vários integrantes (professor, estagiário, Surdo, intérprete). Foram feitas algumas tentativas de elaboração destes sinais, e novos obstáculos começaram a aparecer. João Eduardo coloca que "a ideia inicial é que todo termo [em português] que não possui sinal [em Libras], esse sinal seria criado, o problema é que isso gera muito tempo, você não cria um sinal, "ah eu criei um sinal e é esse", 
não, você tem que conferir com o Surdo, o intérprete, etc.”. João Daniel completa ao perceber o aspecto cultural e de reconhecimento no processo de criação destes termos, que "tem que ser feito por um Surdo, ele tem que criar, a comunidade tem que aceitar” os sinais criados. Mas, complementa: como havia várias "disciplinas que possuem muitos termos técnicos próprios [e] que não [possuem] sinais, a gente caiu de novo num outro problema com relação a isso". Houve assim uma dupla problemática identificada: (1) o processo demorado de criação dos sinais, que envolve várias fases e diferentes pessoas; (2) o processo de aceitação por parte da comunidade Surda, que poderia não adotar (e, por conseguinte, rejeitar) o sinal criado. Era necessário um momento criativo e de aceitação por parte da comunidade Surda. Como havia uma data estipulada de curto prazo para entrega dos materiais, tal caminho, ainda que mais eficaz no âmbito da comunicação dos significados, foi abandonado. A alternativa encontrada foi utilizar a datilologia da palavra, imagens ilustrativas e classificadores.

Após esse processo de idas-e-vindas, chegou-se a uma metodologia de criação de materiais para Surdos intitulada aula sinalizada (Souza \& Júnior, 2016). Este método é uma adaptação de um método já existente, aula narrada, porém em versão de sinais. Esse método estipula alguns passos. Inicialmente, os estagiários em conjunto com os professores da disciplina, montam um material em slide. Esse slide é passado para o estagiário com conhecimento em Libras que traduz o material, com revisão do coordenador do setor de acessibilidade, também fluente em Libras. Depois, é montada uma glosa, ou seja, a transposição escrita da sintaxe do que é sinalizado em Libras para Língua Portuguesa, com a adição de códigos que levem ao entendimento da gramática que compõe a Libras (Ferreira Brito, 1995). Com o auxílio de um audioguia, faz-se um vídeo do intérprete sinalizando a glosa. Ainda que o vídeo seja em Libras, há necessidade de um audioguia que instrua o intérprete na sinalização e também auxilie o editor no momento da edição do vídeo.

Com todos esses materiais prontos, o processo de edição do vídeo é feito. Essa fase também precisou passar por adaptações, pois se percebeu que o quadro com o intérprete costuma ser muito pequeno, o que dificulta a visualização dos detalhes. Para a confecção desse material, da tela foi destinada para a interpretação em Libras. O enquadramento do vídeo foi assim adaptado. Para possibilitar livre movimento, a distância definida foi espaço de um palmo acima da cabeça, nas laterais, a distância dos cotovelos abertos formando dois triângulos com as mãos entrelaçadas no peitoral. 


\subsection{Os reflexos do projeto: efeitos inesperados}

Todo este complexo, esta trama levada adiante por uma demanda de construção de materiais didáticos acessíveis ao estudante Surdo teve uma série de subefeitos não esperados: disseminação de conhecimentos referentes a Libras e às especificidades culturais e cognitivas dos Surdos, necessidade de formação especializada no ensino superior, intensificação das discussões a respeito da produção de materiais didáticos acessíveis. Isso gerou um processo de tomada de consciência e a retificação das "racionalizações" estigmatizadas que Goffman (2012) identifica.

Percebe-se assim uma mudança na posição e na perspectiva dos próprios técnicos, que passaram paulatinamente a compreender a situação do Surdo. Como coloca João Eduardo:

Outra coisa que eu achei interessante foi muito importante, criou até um descompasso entre os professores que geram o conteúdo, é que como a gente teve o grupo de estudos e foi convivendo com os Surdos, a gente entendeu como eles agem e aprendem, que é totalmente diferente da gente.

Por um lado, o que João Eduardo identifica como descompasso se refere a uma tensão conflituosa entre professores da instituição (tidos como especialistas na área em que lecionam) e os próprios membros da equipe de produção do material didático acessível que, ao passarem pelo processo de tomada de consciência da especificidade do modo de ser e de aprender Surdo, acabam por colocar em xeque a capacidade plena dos professores de exercer seu ofício.

Por outro, trata-se de uma potencial multiplicação de informados, daqueles que possuem uma trajetória de experiência que lhes capacita a identificar as dificuldades pelas quais passam os Surdos e a reconhecer essa comunidade como dotada de especificidades e de direitos e, ainda, de competências profissionais e sociais próprias, valorizadas. João Daniel expressa bem essa aprendizagem quando afirma que

o grande avanço para [uma produção sistemática do material didático acessível e, por conseguinte, de uma inclusão social efetiva] acontecer aqui na [Instituição] seria a gente ter o Surdo para trabalhar aqui com a gente, trabalhar aqui em a gente que eu falo tanto no nosso setor de texto, de produção textual, também um Surdo poderia ajudar muito lá, entendeu? Teria que ter um funcionário Surdo fazendo parte da equipe porque é aquela história, como que eu vou trabalhar numa segunda língua, numa outra linguagem sem ter uma pessoa que é nativa daquela língua, precisaria ter. 
É nesse processo dinâmico de interação que os processos reflexivos e os conflitos que os permeiam adquirem relevância já que permitem evidenciar que as "práticas de construção da cidadania” (Fonseca et al., 2016, p. 14) estão longe de serem consensuais, remetendo antes a um renitente fazer cotidiano e reflexivo que configura antes um sociação simmeliana que um realização estática de uma cidadania ideal prevista legalmente. É neste sentido que estamos de acordo com Simmel quando afirma que o conflito é indispensável à coesão grupal, já que é uma condição para a manutenção do processo que unifica e, ao mesmo tempo, transforma grupos sociais. Ele atua não apenas de uma força desagregadora, mas também enquanto força integradora do grupo (Simmel, 1983a).

No nosso caso aqui analisado, a tensão aparece no processo de absorção de conhecimentos da cultura Surda, do modo de ser e comunicar Surdo, que deslocam a posição dos membros da equipe no sentido de se afastarem da posição típica do senso comum (dos “normais”) e se aproximar da posição dos "informados” criando, não obstante, uma ponte possível de relações sociais entre "normais" e "estigmatizados" (Goffman 2012). Essas "antíteses e sínteses" (Simmel, 1983c), sobrepostas umas às outras, provêm do caráter dinâmico deste processo que tem efeitos não apenas sobre a população-alvo da política de inclusão, mas principalmente sobre os encarregados de executar as atividades voltadas para tal propósito. Essas forças centrípetas e centrífugas são dinâmicas e pautam o processo de construção identitária dos vários grupos envolvidos. A importância da forma das relações sociais em Simmel aparecem, no caso aqui trabalhado, como os modos padronizados de relações entre estigmatizados-informados-normais (Simmel, 1983b).

Foi absorvendo e refletindo sobre a problemática da cultura Surda, da comunidade Surda, das especificidades desta população e dos modos adequados de construção de materiais didáticos voltados para esse grupo que se logrou acumular a competência técnica e cultural para criar não só os materiais didáticos específicos das disciplinas mas também desenvolver uma metodologia adequada de construção de materiais didáticos acessíveis.

\section{Considerações finais}

Foi possível perceber, ao longo do texto, que a execução de políticas públicas voltadas para a diminuição da desigualdade social, permeando o avanço formal e o reconhecimento jurídico-legal dos direitos de grupos e populações minoritárias não soluciona por si só o déficit de cidadania que marca nossa existência social. A 
execução concreta dos preceitos igualitários destas políticas nos leva a uma complexificação ainda maior destes processos sociais de transformação. Tendo em vista tal problemática, a reflexão sobre as experiências de formulação e de execução de políticas são fundamentais não só para se poder avaliar o grau de eficácia na sua implementação mas também para se extrair lições no sentido de aperfeiçoá-las e corrigi-las em suas trajetórias.

A análise do processo pelo qual passou uma equipe responsável pela produção de materiais didáticos acessíveis a partir do seu próprio relato dessa experiência nos auxilia a compreender melhor o processo de execução de projetos que visam a efetivar uma política de inclusão social e, ainda, de reconhecimento da diversidade no âmbito de uma instituição de ensino superior. Pode-se dizer que não basta que as equipes dos projetos criem as tecnologias e os materiais didáticos com a intenção e o objetivo de promover a acessibilidade e inclusão. É necessário ainda - e este é um ponto fundamental - que a própria comunidade de usuários aceite e reconheça o material enquanto apto a tal objetivo.

Tais considerações justificam não só a inclusão dos usuários dos materiais nas equipes de criação de materiais didáticos voltados para seu usufruto mas igualmente nos comitês de formulação das políticas públicas voltadas para inclusão. Como diz Michel Callon (1995), os processos de concepção e de difusão das tecnologias não se separam nitidamente entre si: os usuários das tecnologias estão presentes desde o processo inicial de concepção, e esta nunca termina, mesmo após o processo de difusão da tecnologia ter se tornado relevante. A eficiência e a eficácia destes materiais didáticos voltados para inclusão não se limitam a seus aspectos técnicos ou mesmo pedagógicos: há um elemento social e cultural fundamental no qual a tecnologia só poderá existir se for reconhecida enquanto tal pelo grupo de usuários. Qual é a rede que permitirá a adoção e utilização destes materiais? Quem são as pessoas encarregadas em disseminar as informações e as competências que permite tal utilização?

A problemática metodológica e inclusiva apareceu de maneira clara: o processo de construção do material didático inclusivo deve levar em conta o Surdo enquanto parte ativa neste processo de modo a aumentar a eficácia pedagógica do conteúdo elaborado. A temática da aprendizagem Surda, que passa de maneira central na imagem e nas configurações visuais de sua língua, demanda não apenas uma sensibilidade por parte dos professores e daqueles responsáveis pela criação pedagógica: demanda, sim, uma incorporação do Surdo e de sua cultura nos modos de se realizar 
os processos de ensino/aprendizagem. Ao longo do processo, a sua inclusão é, ao mesmo tempo, uma transformação recíproca que enriquece o processo pedagógico ao promover a reflexividade sobre os modos de ensino/aprendizagem.

Tendo em vista que é através da interação que alguns dos processos fundamentais de aprendizagem se dão, devemos notar que esta aprendizagem se refere ao processo que os responsáveis pela produção dos materiais têm que passar para poderem construir as tecnologias didáticas inclusivas. Para superar tais dificuldades, foi possível demonstrar a importância do intermediador na resolução de problemáticas ligadas à diversidade cultural e, ainda, evidenciar os efeitos não-esperados de uma política voltada para a inclusão.

Percebe-se, ao fim do processo de elaboração das aulas sinalizadas, que vários dos impactos provocados pela política pública de acessibilidade e inclusão não se restringem à população alvo: são os "normais" de Goffman que passam por um processo de ressituação no mundo e de aprendizagem cidadã. A execução das atividades tendo em vista a política mais ampla de inclusão provoca, assim, um efeito não-intencional-porém-desejado das ações promovidas em seu nome: o de multiplicar as pessoas aptas a promoverem processos de inclusão social. É isso que provê uma maior capacidade de identificar os nós centrais e problemáticos das políticas de inclusão social e, por conseguinte, de propor soluções viáveis para que um processo de transformação social inclusiva, via prática pedagógica, se dê.

É possível ver que a problematização da situação de interação normal-estigmatizado provocada pelos projetos foi elaborada a partir de um processo reflexivo comandado por um informado (aquele que sabe Libras e que de maneira correlata tem acesso à cultura Surda) via um trabalho coletivo que envolveu a apresentação dos modos de comportamento da comunidade Surda e a organização da memória deste processo de interação - via relatórios e outras produções textuais - com vistas a viabilizar e desenvolver a produção do material didático acessível. Pode-se nelas perceber: (1) a importância de um "informado" para criar as pontes com a comunidade de Surdos e viabilizar o acesso às informações e conhecimentos necessários para a criação do material; (2) a transformação destas pessoas no processo de tomada de consciência de uma diferença que deixa, paulatinamente, de ser estigmatizada e passa a ser normatizável, aproximando-os da posição de "informado".

O processo de elaboração de aulas sinalizadas demonstrou que, embora ocorressem várias dificuldades ligadas à produção de material didático inclusivo, foi possível gerar momentos de reflexão acerca das políticas inclusivas e da imersão delas na rea- 
lidade educacional. Esses entraves provocam novos olhares no sentido de reescrever as trajetórias e de apontar ações passíveis de incluir. Tais desdobramentos serão contextualizados como meio de análise que repercutem nos saberes, nas rotinas, nas experiências e nos efeitos que constituem as políticas de inclusão no Brasil e que adentram o ensino superior.

E, adicionalmente, é possível defender o argumento que as políticas públicas de inclusão ensinem mais àqueles que aparentemente se posicionam no ponto "estabelecido" da normalidade social ao perceberem que há muito a ser aprendido sobre si próprio daqueles que, habitualmente, estão na posição subalterna de nossa sociedade.

Recebido: $14 / 02 / 2019$

Aprovado: 10/04/2019

Ana Luisa Borba Gediel é antropóloga e professora do Departamento de Letras da Universidade Federal deViçosa. Atua na área de Língua Brasileira de Sinais - LIBRAS e é vinculada ao programa de pós-graduação em Letras, na linha de pesquisa Linguística Aplicada: Formação de Professores e Ensino e Aprendizagem de Línguas. Também é professora do Mestrado interinstitucional em Antropologia Social realizado em parceria entre o PPGAS/Museu Nacional/UFRJ e o DCS/UFV. Número de ORCID: 0000-0001-5755-2592.Contato: ana.gedielufv@gmail.com

Victor Luiz Alves Mourão é professor Adjunto do Departamento de Ciências Sociais da Universidade Federal de Viçosa, é doutor em sociologia pelo Programa de Pós-graduação em Sociologia no Instituto de Estudos Sociais e Políticos (IESP-UERJ). Graduado em Ciências Sociais pela UFMG, é mestre em sociologia pelo antigo IUPERJ, realizando estudos na área de estudos sociais da ciência e tecnologia, teoria sociológica, desenvolvimento e inovação. Número de ORCID: 0000-00032770-721X. Contato: vmourao@ufv.br 
Isabela Martins Miranda é graduada em Secretariado Executivo Trilíngue pela Universidade Federal de Viçosa. Atua nos campos de pesquisa voltados para produção de tecnologias da informação e comunicação (TICs) a fim de atender a comunidade surda. Número de ORCID: 0000-0003-1401-0528. Contato: isabelamartinsmiranda@gmail.com

\section{Notas}

1. O projeto de pesquisa foi submetido ao Comitê de Ética em Pesquisa, sendo aprovado pelo mesmo. CAEE: 81077517.6.0000.5153.

2. Classificadores são constituintes do léxico nativo da Libras, em que as configurações de mãos e a orientação de mão são elementos importantes para exercer uma função descritiva, auxiliando na qualificação e significação do que está sendo expresso.

3. Descrevemos no corpo do texto a palavra surdo(s), seguindo a descrição específica utilizada por Assis (2011), referente às categorias deficiente e surdo.

\section{Referências Bibliográficas}

ASSIS SILVA, César A. 2011. Entre a deficiência e cultura: análise etnográfica de atividades missionárias com surdos. Tese [Doutorado em Antropologia Social]. São Paulo: FFLCH/USP.

BARNES, John. A. 1987. Redes sociais e processo político. In: FELDMAN-BIANCO, Bela et al. (ed.). Antropologia das sociedades contemporâneas. São Paulo: Global. p. 159-193.

BRITO, Fábio B. de. 2016. O movimento surdo no Brasil: a busca por direitos. Journal of Research in Special Educational Needs, v. 16, n. s1, p. 766-769.

CALLON, Michel. 1995. Technological Conception and Adoption Network: Lessons for the CTA Practitioner. In: RIP, Arie; MISA, Thomas J. et al. Managing Technology in Society. London, New York: Pinter. p. 307-330.

CARNIEL, Fagner. 2013. A invenção (pedagógica) da surdez: sobre a gestão estatal da educação especial na primeira década do século XXI. Tese [Doutorado em Sociologia Política]. Florianópolis: Universidade Federal de Santa Catarina, Centro de Filosofia e Ciências Humanas.

CARDOSO DE OLIVEIRA, Roberto. 1996. O trabalho do antropólogo: olhar, ouvir, escrever. Revista de Antropologia (USP), v. 39, n. 1, p. 13-37.

Da SILVA, Marilda. 2009. Complexidade da formação de professores: saberes teóricos e saberes práticos. São Paulo: Editora UNESP.

DEDECCA, Claudio S. 2014. A queda da desigualdade de renda corrente e a participação do $1 \%$ de domicílios de maior renda, 2000-2001. Revista de Economia Política, v. 34, n. 2, p. 249-265.

FERREIRA-BRITO, Lucinda. 1995. Por uma gramática de línguas de sinais. Rio de Janeiro: Tempo Brasileiro.

FONSECA, Claudia.; JARDIM, Denise.; SCHUCH, Patrice \& MACHADO, Helena. 2016. Apresentação. Horizontes Antropológicos, v. 22, n. 46, p. 9-34. 
FOUCAULT, Michael. 2001. Os anormais. São Paulo: Martins Fontes.

FRASER, Nancy. 2006. Da redistribuição ao reconhecimento? Dilemas da justiça numa era "pós-socialista". Cadernos de Campo, n. 14/15, p. 31-239.

FRASER, Nancy; HONNETH, Axel. 2003. Redistribution or recognition? A political-philosophical exchange. New York: Verso.

GESSER, Audrei. 2009. LIBRAS? Que língua é essa? Crenças e preconceitos em torno da língua de sinais $e$ da realidade surda. São Paulo: Parábola.

GIDDENS, Anthony. 2007. A constituição da sociedade. São Paulo: Martins Fontes.

GLAT, Rosana; PLETSH, Márcia D. 2010. O papel da Universidade no contexto da política de Educação Inclusiva: reflexões sobre a formação de recursos humanos e a produção de conhecimento. Revista Educação Especial, Santa Maria, v. 23, n. 38, p. 345 -356.

GOFFMAN, Erving. 2012. Estigma: notas sobre a manipulação da identidade deteriorada. 4. ed. Rio de Janeiro: LTC.

IMBERNÓN, Francisco. 2010. Formação docente e profissional: formar-se para a mudança e a incerteza. 7. ed. São Paulo: Cortez.

LATOUR, Bruno. 2000. Ciência em Ação. Como seguir cientistas e engenheiros sociedade afora. São Paulo: Editora Unesp.

PADDEN, Carol; HUMPHRIES, Tom. 2006. Inside Deaf Culture. Cambridge, Massachusetts: Harvard University Press.

QUADROS, Ronice M. \& KARNOPP, Lodenir. 2004. Língua de Sinais brasileira: estudos linguísticos. Porto Alegre: Artmed.

SANTOS, Emmanuelle F. 2015. Tecendo leituras nas pesquisas sobre Libras: sentidos atribuídos ao seu ensino na educação superior. In: ALMEIDA, Wolney G. (ed.). Educação de surdos: formação, estratégias e prática docente [online]. Ilhéus, BA: Editus, p. 67-91.

SIMMEL, Georg. 1983a. A natureza sociológica do conflito. In: MORAES FILHO, Evaristo (ed.). Georg Simmel: sociologia. São Paulo: Ática. p. 122-134.

1983b. Como as formas sociais se mantêm. In: MORAES FILHO, Evaristo (ed.). Georg Simmel: sociologia. São Paulo: Ática. p. 46-58.

. 1983c. Conflito e estrutura de grupo. In: MORAES FILHO, Evaristo (ed.). Georg Simmel: sociologia. São Paulo: Ática. p. 150-164.

SOUZA, André. L. S. D.; JÚNIOR, José T. 2016. O uso de tecnologias (TIC) na produção de material didático bilíngue libras/português na Universidade Federal de Viçosa. Revista Fórum (INES), n. 33, p. 92-109.

TRIVIÑOS, Augusto N. S. 1987. Introdução à pesquisa em ciências sociais: a pesquisa qualitativa em educação. São Paulo: Atlas. 
A inclusão e suas práticas: aspectos socioantropológicos da produção de materiais pedagógicos inclusivos para Surdos

Resumo: O cenário da expansão de políticas públicas que ocorreu nas últimas décadas pressionou por um conjunto de novos arranjos nas instituições educativas tendo em vista a inclusão de pessoas com deficiência. $\mathrm{O}$ presente artigo tem o objetivo de descrever o trabalho de elaboração de materiais didáticos para a inclusão de uma pessoa Surda em uma instituição de ensino superior. Nos interessa refletir acerca da reflexividade e dos conflitos envolvendo os pontos de vista dos profissionais de diferentes áreas de especialidade que atuam na Unidade de Ensino à Distância para o processo de elaboração dos materiais e as ações institucionais que conformam essa conjuntura. Acessamos os agentes envolvidos a partir da metodologia de redes e pontuamos os principais elementos norteadores e transformadores do processo. Entendemos que as políticas públicas são de extrema importância para gerar oportunidades de mudança e observamos a complexidade na delimitação e efetivação de ações para atender à diversidade socialmente existente, e que as transformações que suscitam ultrapassam o âmbito dos seus destinatários explícitos.

Palavras-chave: políticas públicas, ensino superior, inclusão social, pessoas Surdas.
Inclusion and its practices: socio-anthropological aspects of the production of Deaf-inclusive pedagogical materials

Abstract: The trajectory of Brazilian public policies in the last decades promoted new arrangements in educational institutions which had at its objectives the effective inclusion of people with disabilities. This article aims to describe the experience of developing didactic materials for the inclusion of a Deaf person in a higher education institution. We are interested in reflecting on the reflexivity and conflicts involving distinct points of view of the professionals from different areas of knowledge surrounding the process of elaboration of those materials and the institutional actions that conformed this conjecture. We accessed the agents involved through the methodology of networks and we point out the main guiding and transforming elements of this process. We understand that public policies are extremely important in order to generate opportunities for social change and we observe the complexity in delimiting and implementing actions to meet current social heterogeneity, and that the transformations which it provoked went beyond their explicit destinataries.

Keywords: public policy, higher education, social inclusion, Deaf people. 